\title{
Основы мониторинга строительных объектов в период эксплуатации с ис- пользованием анализа изменения их динамических параметров
}

\author{
В.В.Гурьев, ЦНИИП Минстроя России, Москва \\ В.М.Дорофеев, ФЦС, Москва \\ Д.А.Лысов, ЦНИИпромзданий, Москва \\ Р.Т.Акбиев, ЦНИИП Минстроя России, Москва
}

Работа посвящена проблемам контроля технического состояния зданий и сооружений в период эксплуатации. Теоретические основы такого контроля базируются на анализе изменения динамических характеристик объектов, вызываемых соответствующим изменением их технического состояния. Рассмотрены возможности анализа изменения периода и декремента основного тона собственных колебаний зданий и сооружений или их конструктивных элементов, в том числе и в соответствии с действующей нормативной базой по этому вопросу. Представлены практические результаты по точности определения этих динамических параметров зданий и сооружений. Приведены результаты разработки специальных способов контроля технического состояния конструкций высотных и большепролётных зданий и сооружений, основанных на анализе изменения передаточных функций для динамических сигналов прошедших через заданный объём их конструкций. При этом рассмотрены случаи как задания динамических воздействий в виде широкополосного импульса, так и задания воздействий в виде гармонических колебаний. Приведены примеры возможности контроля технического состояния отдельных конструктивных элементов зданий и сооружений на основе анализа изменения их динамических параметров. Отмечено, что представленные способы контроля технического состояния зданий и сооружений положены в основу как нормативных документов по такому контролю, так и в основу разработанных стационарных систем (станций) мониторинга технического состояния зданий и сооружений. Предложено рассмотренные теоретические основы контроля технического состояния зданий и сооружений использовать для цифровой трансформации национальной системы мониторинга состояния и безопасности строительных объектов в период эксплуатации.

Ключевые слова: эксплуатация зданий и сооружений, контроль технического состояния, теоретические основы, анализ изменения динамических параметров, мониторинг технического состояния.

Foundations of Monitoring for Structural Obiects during Exploitation on the Base of Analysis of Changes in Its Dynamic Parameters

V.V.Guryev, TsNIIP Minstroy Russia, Moscow

V.M.Dorofeev, FCS, Moscow

D.A.Lysov, TsNIIPromzdanii, Moscow

R.T.Akbiev, TsNIIP Minstroy Russia, Moscow
The article is concerned with the monitoring of the technical condition of buildings and structures during their exploitation and use. Theoretical foundations for the monitoring are based on the analysis of changes of objects' dynamic characteristics associated with corresponding changes in their technical condition.

The capabilities of the analysis of change of the period and the damping factor at the fundamental frequency of oscillations of buildings and structures as well as their elements are considered taking into account the current normative documentation, codes, and regulations on this topic. Practical results on the accuracy of determination of these dynamic parameters of buildings and structures are presented.

The results of the development of special methods for monitoring of technical conditions of high-rise buildings and long-range constructions are also presented. These methods were developed based on the analysis of changes in transfer functions of dynamic signals propagated through the given volume of the construction. The dynamic signals can be both broadband pulses and harmonic oscillations - both forms of excitation are considered.

Examples are given demonstrating the capabilities of the presented methods for monitoring the state and technical conditions of the construction elements of buildings and structures based on the analysis of their dynamic parameters. The presented methods were used as a basis for both normative documents and to develop stationary systems (stations) for monitoring the technical conditions of buildings and structures.

The proposed theoretical foundations can be used for the digital transformation of the national system for monitoring of safety and state of buildings and structures during exploitation.

Keywords: exploitation of buildings and constructions, control of technical condition, theoretical foundations, analysis of change of dynamic parameters, monitoring of technical condition.

В соответствии с частью 1 статьи 36 Технического регламента о безопасности зданий и сооружений [1] «безопасность здания или сооружения в процессе эксплуатации должна 
обеспечиваться посредством технического обслуживания, периодических осмотров и контрольных проверок и (или) мониторинга состояния основания, строительных конструкций и систем инженерно-технического обеспечения, а также посредством текущих ремонтов здания или сооружения».

В соответствии с частью 1 статьи 40 этого закона «обязательная оценка соответствия зданий и сооружений, а также связанных со зданиями и с сооружениями процессов эксплуатации требованиям закона и требованиям, установленным в проектной документации, осуществляется в форме: 1) эксплуатационного контроля; 2) государственного контроля (надзора)».

Оценка соответствия зданий и сооружений, а также связанных со зданиями и с сооружениями процессов эксплуатации осуществляется в целях периодического подтверждения соответствия характеристик эксплуатируемого здания или сооружения требованиям закона [1] и проектной документации для установления возможности дальнейшей эксплуатации здания или сооружения [1, ч.1, ст. 38]. Для оценки соответствия зданий и сооружений в период их эксплуатации осуществляются обследования этих объектов в соответствии с требованиями [2]. Стоимость такого обследования зависит от конструктивных особенностей строительных объектов, их объёмов, планировочной структуры и др. Для крупных населённых пунктов с сотнями и тысячами зданий и сооружений, а также для крупных промышленных объектов процессы обследования не только трудоёмки и финансово затратны, но и требуют привлечения большого количества профессиональных кадров. При этом часто такие обследования не приводят к какому-либо новому результату.

Реальное состояние зданий и сооружений по ряду причин (несовершенство и недостаточность информации о природнотехногенном воздействии и методах проектирования, недостаточное качество строительства и строительных материалов, эксплуатационный износ зданий и сооружений и др.) может существенно отличаться от проектных значений. Для повышения эффективности мероприятий по обеспечению безопасности функционирования зданий и сооружений необходима разработка методик выявления из огромного числа зданий и сооружений города тех, которые требуют более детального исследования их технического состояния, то есть выявления зданий и сооружений, состояние которых наиболее сильно изменилось за определённый нормативно устанавливаемый срок или приблизилось к критическому состоянию.

Наиболее совершенным и экономически целесообразным для реализации способом определения изменений состояния зданий и сооружений следует признать способ регистрации изменений периодов и коэффициентов затухания основного тона собственных колебаний зданий и сооружений и при необходимости их обертонов (смотри, например, [3; 4]).

В основе способа лежит известная из физики особенность твёрдых тел изменять частоты (периоды) собственных колебаний при изменении их физического состояния. Эти динамические параметры являются интегральными параметрами зданий и сооружений, они полностью определяются их состоянием и реагируют как на изменения структуры зданий и сооружений (для случая их частичных повреждений и разрушений), так и на внутренние необратимые процессы (для случая накопления повреждений в процессе эксплуатации). Кроме того, они достаточно легко могут быть измерены, в том числе автоматически, например, с помощью цифровых акселерографов по текущим колебаниям микродинамического фона естественного и техногенного происхождения, которые имеют достаточный для произведения измерений уровень на территории любого города. Методика их определения по записям колебаний, зарегистрированных на конструкциях зданий и сооружений, приведена в [5], на основе которой разработан норматив [6].

В соответствии с $[5 ; 6]$ средний период для серии из $n$ записей определяется по формуле:

$$
T_{c p}=\frac{\sum_{i=1}^{n} T_{i}}{n},
$$

а среднеквадратическое отклонение $\sigma_{\mathrm{T}}$ - по формуле:

$$
\sigma_{T}=\sqrt{\frac{\sum_{i=1}^{n}\left(T_{i}-T_{c p}\right)}{n(n-1)}},
$$

где $T_{\mathrm{i}}=1 / f_{\mathrm{i}}$, а $f_{\mathrm{i}}$ - значение частоты, при которой достигается максимум нормированного спектра мощности записи колебаний.

Средний декремент колебаний $D_{\text {ср }}$ и его среднеквадратическое отклонение $\sigma_{\text {D }}$ определяются по аналогичным формулам, при этом $D_{\mathrm{i}}=\pi\left[\left(f_{\mathrm{B}}\right)_{\mathrm{i}}-\left(f_{\mathrm{H}}\right)_{\mathrm{i}}\right] / f_{\mathrm{i}}$, где $\left(f_{\mathrm{B}}\right)_{\mathrm{i}}-\left(f_{\mathrm{H}}\right)_{\mathrm{i}}$ ширина полосы пропускания, то есть частотная полоса, на границах которой энергия системы вдвое меньше энергии на собственной частоте.

Результаты измерений представляются в следующем виде:

$$
\begin{aligned}
T & =T_{\text {ср }} \pm \Delta_{\mathrm{T}}-\text { при заданной вероятности } p, \\
D & =D_{\mathrm{cp}} \pm \Delta_{\mathrm{D}}-\text { при заданной вероятности } p,
\end{aligned}
$$

где $\Delta_{\mathrm{T}}, \Delta_{\mathrm{D}}$ - абсолютные погрешности измерения периода и декремента соответственно; $p$ - доверительная вероятность определения погрешности.

Для выбранных значений $n$ и $p$ абсолютные погрешности измерений равны:

$$
\Delta_{\mathrm{T}}=\mu(n, p) \sigma_{\mathrm{T}}, \Delta_{\mathrm{D}}=\mu(n, p) \sigma_{\mathrm{D}},
$$

где $\mu(n, p)$ определяют по таблице функции распределения Стьюдента при $n \leq 20$ или по таблице функции Лапласа при $n>20$.

Опыт использования приведённой технологии для определения периода и логарифмического декремента основного тона собственных колебаний зданий в городе Москве [5], показал, 
что при $n=20$ и $p=0,9$ ошибка измерения периода не превышает $2 \%$, а логарифмического декремента колебаний - $5 \%$.

Измерение динамических параметров зданий и сооружений (периодов и коэффициентов затухания) проводят для выявления объектов, изменение напряжённо-деформированного состояния которых требует обследования их технического состояния. В соответствии с п. 2.6.4 межгосударственного стандарта ГОСТ 31937-2011 критическим изменением является 10-процентное изменение периода основного тона собственных колебаний здания или сооружения.

Следует отметить, что изложенные выше соображения в полной мере относятся и к конструктивным элементам зданий и сооружений. Так, например, период основного тона железобетонной колонны во время набора прочности бетоном может увеличиться, а в последующий период деградации её материала - уменьшиться.

Для высотных и большепролётных зданий и сооружений рассмотренная и эффективная для обычных зданий методика контроля их технического состояния малопригодна. Дело в том, что с увеличением количества этажей, то есть высоты здания, или увеличения длины пролётов сооружений вклад изменения напряжённо-деформированного состояния какой-либо части этого зданий в величины периодов и логарифмических декрементов собственных колебаний становится всё меньше и меньше. Это обстоятельство требует существенного увеличения точности измерений этих величин или дополнительного изучения обертонов собственных колебаний таких зданий и сооружений, что сопряжено с рядом весьма существенных технических трудностей, в основном связанных с увеличением чувствительности аппаратуры и выявлением интервалов изменения периодов обертонов собственных колебаний объектов.

Кроме того, даже выявленные изменения в периодах и логарифмических декрементах колебаний свидетельствуют лишь о необходимости проведения традиционного обследования всего здания или сооружения с определением конкретных изменений в конструкциях для их последующей безопасной эксплуатации. Такой подход экономически малопригоден для высотных и большепролётных зданий и сооружений в силу чрезмерной трудоёмкости и высокой стоимости выполнения большого объёма обследований, а также не позволяет локализовать места изменения напряжённо-деформированного состояния конструкций здания.
Для решения проблемы разработан способ динамического зондирования и ранней диагностики деформационного состояния несущих конструкций, основанный на анализе изменения передаточных функций, полученных для различных по высоте участков здания [3]. Способ применим и для протяжённых в плане зданий, в этом случае передаточные функции строятся для различных участков здания вдоль протяжённой оси.

В основе способа, как и раньше, лежит физическая закономерность, связывающая изменение состояния твёрдого тела с изменением его динамических параметров (частот собственных колебаний), которые в данном случае для объектов определяются с использованием передаточных функций, получаемых с помощью искусственно задаваемого воздействия:

$$
W_{j}\left(\varphi_{j}\right)=\frac{P_{j}\left(\varphi_{j}\right)_{\text {Bbx }}}{P_{j}\left(\varphi_{j}\right)_{\text {ex }}},
$$

где $P_{\mathrm{j}}\left(\varphi_{\mathrm{j}}\right)_{\theta x}$ - спектр мощности входного сигнала (воздействия), $P_{\mathrm{j}}\left(\varphi_{\mathrm{j}}\right)_{\text {вых }}$ - спектр мощности выходного сигнала, $\varphi_{\mathrm{j}}-$ текущая частота сигнала, $j$ - номер текущей частоты сигнала (в разложении ряда Фурье сигнала при построении спектров мощности сигнала).

Для построения передаточной функции части здания, как отмечено в [7], используются компоненты спектров мощности зарегистрированных сигналов в двух точках здания, а именно - в месте динамического воздействия, заданного в виде, например, широкополосного импульса, и в месте регистрации отклика этого воздействия, прошедшего через рассматриваемую часть здания. Такая передаточная функция характеризует напряжённо-деформированное состояние конструкций именно в той части здания, через которое прошёл заданный широкополосный импульс (рис. 1). Изменение передаточной функции (изменение величин коэффициентов усиления для различных частот) свидетельствует об изменении напряженно-деформированного состояния конструкций именно в этой части здания. Таким образом, удается не только выявить изменение напряженно-деформированного состояния конструкций здания, но и локализовать места такого изменения в пределах количества этажей здания (для случая вертикального расположения точек измерения) межу соседними точками измерения. Для высотных зданий целесообразно

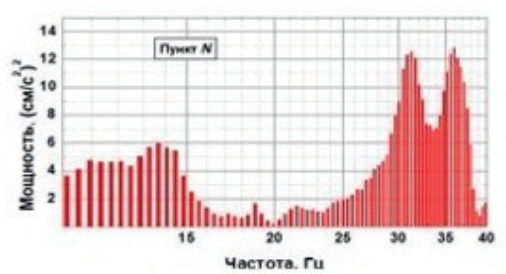

a)

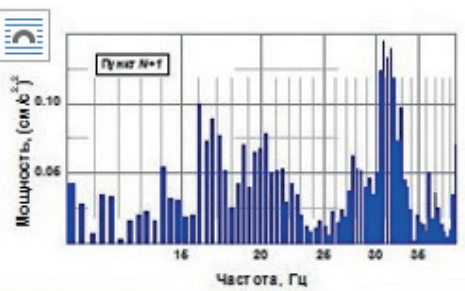

б)

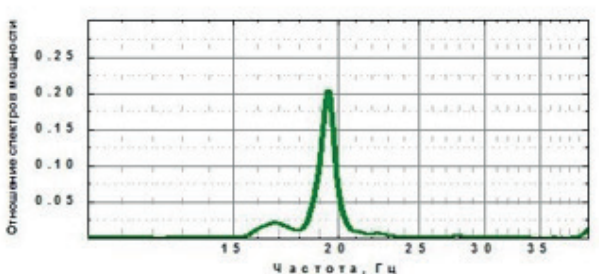

B)

Pис. 1. Спектры мощности входного и выходного сигналов для построения передаточной функции: а) спектр мощности входного сигнала (воздействия) $\left.P_{\mathrm{j}}\left(\varphi_{\mathrm{j}}\right)_{\text {вх }} ; \sigma\right)$ спектр мощности выходного сигнала $\left.P_{\mathrm{j}}\left(\varphi_{\mathrm{j}}\right)_{\text {вых }} ; в\right)$ передаточная функция $W_{\mathrm{j}}\left(\varphi_{\mathrm{j}}\right)$ 
как из соображений технического характера (чувствительности используемой регистрирующей аппаратуры и уровня динамического воздействия), так и из соображений времени и трудоёмкости обследования такого объёма строительных конструкций) проводить измерения через каждые пять этажей, ограничивая область локализации изменения напряжённодеформированного состояния в пределах данной этажности, где при необходимости потребуется проводить традиционное обследование и выяснять степень опасности изменения напряженно-деформированного состояния конструкций.

Задаваемое динамическое воздействие должно перекрывать своим частотным диапазоном область собственных периодов колебаний конструкций исследуемой части здания, а уровень сигнала в этой частотной области должен быть выше уровня динамического шума при измерениях и не сильно отличаться по уровню при различных во времени измерениях в процессе эксплуатации.

В работе [5] приводится анализ условий эффективности такого подхода. Действительно, при регистрации колебаний конструкций получаются две осциллирующие функции $k_{1}$ (регистрация колебаний вблизи места динамического воздействия) и $k_{2}$ (регистрация колебаний отклика динамического воздействия). Функция $k_{1}$ представляет собой сложение задаваемого динамического воздействия $k_{11}$ с динамическим шумом $k_{12}$ распространяющимся в том же направлении, что и задаваемое динамическое воздействие, и с откликом $e_{21}$ на динамический шум $k_{21}$, распространяющийся от места регистрации отклика динамического воздействия в противоположном этому воздействию направлении. Таким образом, $k_{1}$ $=k_{11}+k_{12}+e_{21}$. Аналогичным образом получаем выражение для $k_{2}: k_{2}=e_{11}+e_{12}+k_{21}$ где $e_{11}$ - отклик на задаваемое динамическое воздействие $k_{11}$ a $e_{12}$ - отклик на динамический шум $k_{12}$.

Передаточная функция $W_{\mathrm{j}}$ представляет собой отношение компонент спектров мощности сигналов $e_{11}$ и $k_{11}$. Однако реально в качестве $W_{\mathrm{j}}$ используется некоторая функция $W_{\mathrm{j}}^{*}$, представляющая собой отношение компонент спектров мощности сигналов $k_{2}$ и $k_{1}$, то есть

$$
W_{j}^{i}=\frac{P_{j}\left(k_{2}\right)}{P_{j}\left(k_{1}\right)}=\frac{P_{j}\left(e_{11}+e_{12}+k_{21}\right)}{P_{j}\left(k_{11}+k_{12}+e_{21}\right)},
$$

где через $W_{\text {j }}$ обозначаются спектры мощности сигналов. Эти две функции $W_{\mathrm{j}}$ и $W_{\mathrm{j}}{ }^{*}$ будут близки друг к другу лишь при одновременном выполнении условий $e_{11}>e_{12}+k_{21}$ и $k_{11}>k_{12}+e_{21}$. Это достигается выбором необходимого вида неупругого удара, который реализует выполнение указанных условий в частотной области, перекрывающей собственные частоты исследуемой части высотного здания (части здания, расположенной между двумя измерительными пунктами).

Однако далеко не во всех случаях можно достичь выполнения вышеописанных условий для получения надёжной передаточной функции. Поэтому для решения проблемы часто используется более простой способ, требующий, однако, специального оборудования, возбуждающего гармонические колебания необходимой частоты и уровня.

В этом случае передаточная функция определяется отношением амплитуд возбуждаемого на определённой частоте гармонического колебания и регистрируемого отклика этого колебания на удалении (либо по высоте, либо по протяжённости здания или сооружения).

Для сильно зашумлённого полезного сигнала, метод заключается в «синхронном суммировании», когда в течение интервала времени $\Delta t$ суммируются $n$ отрезков сигнала длительностью $\tau=1 / f$, где $f$ - заданная на данный момент частота колебаний, генерируемая специальным оборудованием. Длительность временного интервала $\Delta t$ определяет коэффициент $F$, представляющий собой отношение уровня сигнала к уровню шума. Смысл термина «синхронность» заключается в необходимости сохранения фазы суммирования на протяжении всего интервала $\Delta t$.

Если $\sigma_{c} и \sigma_{\text {u }}$ - регистрируемые среднеквадратичные значения амплитуд соответственно единичного отклика и шума, то значение отношения сигнала к шуму $F=\sigma_{\text {c }} / \sigma_{\text {u }}$ В результате суммирования среднеквадратичная амплитуда «полезного» сигнала увеличивается как $\sigma_{\Sigma}=n \sigma_{\mathrm{c}}$, а среднеквадратичное значение шума согласно теории случайных процессов - как $\sigma_{\Sigma}=\sigma_{u} \sqrt{n}$, тогда $F_{\Sigma}=\left(\sigma_{\text {с }} \sqrt{n}\right) / \sigma_{u}$. Из отношения $F_{\Sigma} / F=\sqrt{n}$ видно, что в результате операции суммирования получаем выигрыш в отношении сигнала к шуму, пропорциональный квадратному корню из числа просуммированных отрезков сигнала. Так, например, при $n=100$ улучшаем отношение сигнала к шуму в 10 раз.

На рисунке 2 приведены передаточные функции $W$ для 5-этажного участка 16-этажного жилого дома [8], полученные при задании динамического воздействия в виде широко-

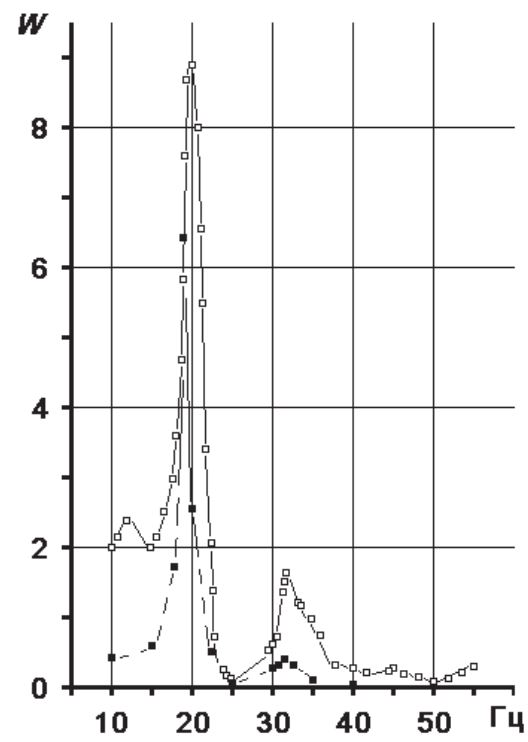

Puc. 2. Передаточные функции W, полученные с помощью импульсного воздействия (口) и источника гармонических колебаний (口) 
полосного импульса и в виде гармонических колебаний от мобильного устройства возбуждения динамической нагрузки [8]. Из сравнения передаточных функций видно, что форма и пики кривых совпадают, за исключением участка 10-17 Гц. Это расхождение связано с низкой надёжностью измерений, выполненных с помощью импульсного динамического воздействия, которая вызвана недостаточным уровнем составляющих импульс компонент в этой частотной области.

Развитием описанного выше способа стал способ определения изменений напряжённо-деформированного состояния конструкций здания или сооружения сложной пространственной формы [9]. Для реализации этого способа осуществляют разделение высотного здания или сооружения сложной пространственной формы вертикальными сечениями на части простой пространственной формы, при этом разделение по высоте на зоны от трёх до пяти этажей производят отдельно для каждой части простой пространственной формы здания или сооружения, выравнивая границы зон для всех частей простой пространственной формы здания или сооружения на уровне первого этажа.

Трёхкомпонентные вибродатчики для регистрации колебаний конструкций устанавливают по вертикальной оси в каждой части простой пространственной формы здания или сооружения. Измерение пространственных колебаний осуществляют на противоположных границах примыкающих зон относительно зоны приложения динамической нагрузки как по высоте, так и по горизонтали на уровне приложения динамической нагрузки в местах установки трёхкомпонентных вибродатчиков примыкающих зон частей простой пространственной формы высотного здания. Процесс определения передаточных функций осуществляется аналогично вышеописанной процедуре.

Для большепролётных зданий и сооружений, характеризующихся сложными многоэлементными конструктивными схемами, разработан специальный способ определения технического состояния строительных конструкций и/или их частей и элементов.

Способ заключается в получении реальных динамических параметров, отображающих техническое состояние строительной конструкции и их сравнение с аналогичными динамическими параметрами, полученными для этой конструкции с помощью математического моделирования. При этом математическое моделирование осуществляется для случая минимально нагруженного состояния конструкции и для случая максимально нормативно нагруженного состояния конструкции, характеризующего его предельную несущую способность. По степени достижения реальной величиной динамического параметра своего предельного значения, полученного с помощью математического моделирования для случая максимально нормативно нагруженного состояния конструкции, судят о техническом состоянии конструкции.

Если в процессе математического моделирования получены значения динамических параметров для различных вариантов ослабления конструкции, то сравнение реальных динамических параметров конструкции с полученными таким путём аналогичными величинами позволяет выявлять конкретные элементы этой конструкции, которые привели к снижению несущей способности конструкции в целом.

Рассмотрим применение описанного выше способа на примере возможности контроля деревометаллической фермы покрытия Ледового дворца «Крылатское» (крытый конькобежный центр) в Москве. Ферма состоит из следующих элементов: верхний пояс представляет собой деревянную балку сечением $1000 \times 280$ мм; нижний пояс представляет собой стальную трубу ø203×20 мм; раскосы представляют собой стальные трубы $\varnothing 168 \times 8$ мм.

Предварительно с помощью математического моделирования были вычислены частоты пяти форм собственных колебаний фермы для случаев минимально нагруженного состояния и максимально нормативно нагруженного состояния, характеризующего её предельную несущую способность.

В таблице 1 представлены вычисленные частоты собственных колебаний фермы по компоненте $Z$ для случаев минимально нагруженного и максимально нормативно нагруженного состояний. Аналогично были вычислены частоты собственных колебаний фермы по компонентам $X$ и $Y$. Из приведённой таблицы видно, что в результате нагружения частота основного тона, первого и второго обертонов собственных колебаний фермы приблизительно изменилась на $34 \%$, третьего обертона на 32\%, четвёртого обертона на $21 \%$.

Аналогичные таблицы были получены для случая удаления среднего раскоса или удаления крайнего раскоса (таблица 2).

Из приведённой таблицы видно, что для первого варианта (фермы с удалённым средним раскосом) основной тон собственных колебаний приблизительно изменился на $1 \%$, первый обертон - на 46\%, второй обертон - на 7\%, третий обертон - на 23\%, четвёртый обертон - на 4\%. Для второго

Таблица 1. Частоты собственных колебаний фермы без повреждения раскосов

\begin{tabular}{|c|c|c|}
\hline 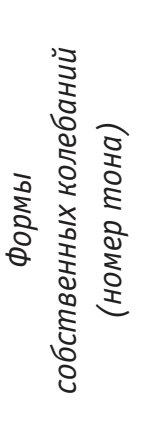 & 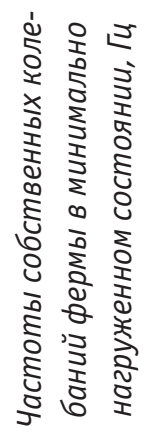 & 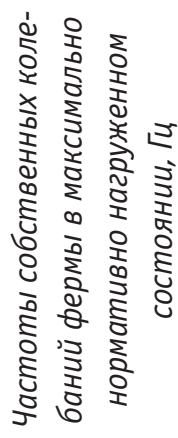 \\
\hline 1 & 3,42 & 2,26 \\
\hline 2 & 8,63 & 5,71 \\
\hline 3 & 13,70 & 9,00 \\
\hline 4 & 17,90 & 12,09 \\
\hline 5 & 19,20 & 15,23 \\
\hline
\end{tabular}


варианта (фермы с удалённым крайним раскосом) основной тон и первый обертон собственных колебаний не изменились, второй обертон приблизительно изменился на 5\%, третий и четвёртый обертоны - на $12 \%$.

Выбор места установки регистрирующего колебания конструкций прибора на ферме производится из условия максимального произведения смещений по используемым для анализа тонам собственных колебаний фермы. Перемножая значения перемещений разных тонов колебаний фермы в заданных узловых точках верхнего пояса, находим, какому из них соответствует максимальная величина произведения. В этой точке наилучшим образом регистрируются все пять тонов, а это означает, что этой точке соответствует максимальное соотношение «сигнал-шум», что позволяет наиболее надёжно контролировать изменение частот собственных колебаний фермы, а, значит, и устанавливать регистрирующий колебания прибор необходимо в районе этого узла.

Для регистрации динамических параметров ферм не осуществляется дополнительное динамическое воздействие, измерения производятся на основе присутствующей фоновой микродинамики города, в том числе и ветровых воздействий.

В соответствии с разделом 6.5 норматива [2] для проведения контроля и ранней диагностики технического состояния оснований и строительных конструкций уникального здания (сооружения) устанавливают автоматизированную стационарную систему (станцию) мониторинга технического состояния (в соответствии с заранее разработанным проектом), которая должна в автоматизированном режиме выявлять изменения напряжённо-деформированного состояния конструкций с локализацией их опасных участков, определение уровня крена здания или сооружения, а в случае необходимости - и других параметров (деформации, давление и др.). Изложенные выше технологии лежат в основе разработки таких стационарных систем (станций) как для мониторинга

таблица 2. Частоты собственных колебаний фермы с удалённым средним раскосом, с удалённым крайним раскосом

\begin{tabular}{|c|c|c|}
\hline 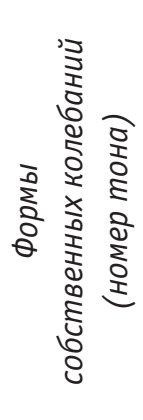 & 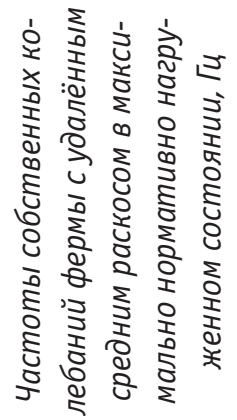 & 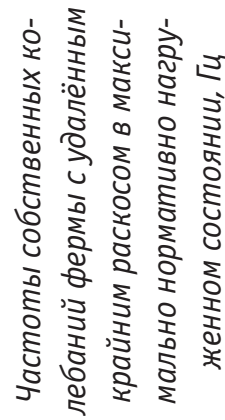 \\
\hline 1 & 2,23 & 2,26 \\
\hline 2 & 3,11 & 5,70 \\
\hline 3 & 8,33 & 8,59 \\
\hline 4 & 9,34 & 10,66 \\
\hline 5 & 14,61 & 13,38 \\
\hline
\end{tabular}

технического состояния уникальных зданий и сооружений, обобщённых в нормативе [12], так и для мониторинга массовой застройки городов и населённых пунктов, расположенных в регионах с особыми природными условиями, в частности в сейсмических районах.

Вообще первое практическое использование динамических параметров зданий и сооружений для их технического состояния было осуществлено в 1920 году именно в сейсмических районах Японии японским учёным А. Имамурой [7] - основоположником инженерно-сейсмометрических наблюдений. В 1967 году Государственный Комитет Совета Министров СССР по науке и технике, Государственный Комитет Совета Министров СССР по делам строительства и Президиум Академии наук СССР приняли постановление о создании в СССР системы инструментальных инженерно-сейсмометрических наблюдений за колебаниями грунта, зданий и промышленных сооружений крупных городов и строек.

Основной задачей инженерно-сейсмометрических наблюдений является получение информации о динамическом поведении сооружений при землетрясениях, которая на каждом этапе развития теории и практики сейсмостойкого строительства давала бы основу для более надёжного проектирования сооружений, создания принципиально новых конструкций и методов расчёта, наиболее полно описывающих реальные физические процессы, происходящие в сооружениях при сейсмических воздействиях, контроля технического состояния застройки городов и населённых пунктов [4; 14; 15].

Системы мониторинга состояния зданий и сооружений существующей застройки городов, постоянно отслеживая это состояние, должны:

1) выявлять здания и сооружения, требующие усиления;

2) давать предложения по очерёдности осуществления превентивных мероприятий с целью повышения безопасности проживания населения;

3) предоставлять исходный материал для проведения обоснованной страховой политики при застройке и эксплуатации строительных объектов;

4) контролировать степень снижения опасности проживания населения, вызываемой мероприятиями по необходимому усилению зданий и сооружений;

5) предоставлять оперативную информацию о состоянии зданий и сооружений сразу же после сильного землетрясения для повышения эффективности проведения спасательных работ и последующей ликвидации последствий землетрясений;

6) предоставлять научную информацию о динамическом поведении зданий и сооружений и о региональных сейсмических воздействиях для совершенствования методов расчёта зданий и сооружений на сейсмостойкость.

Основной первичной исходной информацией для работы такой системы служит информация сети сейсмодатчиков, установленных на различных зданиях города (инженерно-сейсмометрических станций). Такие сейсмодатчики должны быть установлены на достаточно представительных группах зданий 
различных конструктивных решений и всех зданиях, знание о состоянии которых после землетрясения особо важно.

Условия выбора конфигурации сети инженерно-сейсмометрических станций весьма разнообразны и часто противоречивы. Отсюда ясно, что одним из важнейших аспектов развития и совершенствования системы инженерно-сейсмометрических наблюдений является проблема построения оптимальной сети инженерно-сейсмометрических станций $[16 ; 17]$.

Основополагающий СП 14.13330.2018 «Строительство в сейсмических районах» предусматривает установку автоматизированных систем (станций) мониторинга технического состояния этих объектов в соответствии с $[2 ; 6 ; 12]$ и установку инженерно-сейсмометрических станций наблюдения за динамическим поведением конструкций и прилегающих грунтов в соответствии с [18]. Допускается объединение инженерно-сейсмометрических станций с автоматизированными системами (станциями) мониторинга технического состояния в единые измерительные комплексы.

Современные способы и системы мониторинга технического состояния объектов и инженерно-сейсмометрических станций представлены в [19-22].

В качестве примера информации, получаемой на инженерно-сейсмометрических станциях, на рисунке 3 представлена зависимость периода и логарифмического декремента основного тона собственных колебаний от интенсивности сейсмического процесса, полученная на инженерно-сейсмометрической станции, установленной в городе Ереване на шестиэтажном каменном жилом здании с тремя продольными несущими стенами. Представленная информация получена по записям колебаний на этой станции при землетрясении интенсивностью 4-5 баллов по шкале MSK-64 произошедшем 25 февраля 1978 года [4].

Строительные нормы, регламентирующие сейсмостойкое строительство, касаются обеспечения лишь первоначальной сейсмостойкости возводимых сооружений и не связаны с вопросами эволюции этой сейсмостойкости. Реальная сейсмостойкость зданий и сооружений по ряду причин (несовершенство и недостаточность информации о прогнозируемых сейсмических воздействиях и методах проектирования, недостаточное качество строительства и строительных ма-
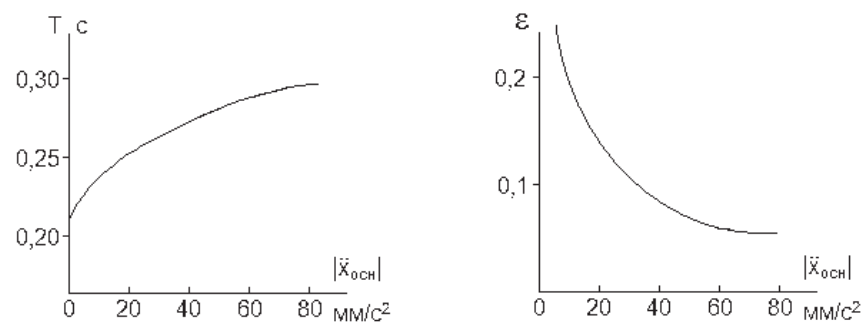

Рис. 3. Графики зависимости периода собственных колебаний Т каменного здания города Еревана и его коэффициента затухания \& от интенсивности сейсмического воздействия (источник: [4]) териалов, эксплуатационный износ зданий и сооружений и несовершенство их реконструкции, изменение свойств специальных систем сейсмозащиты во времени и др.) может существенно отличаться от требующейся для данной площадки в населённом пункте.

Реальная сейсмостойкость здания или сооружения характеризуется классом сейсмостойкости, зависящим от уровня расчётного сейсмического воздействия, на которое проектировалось здание или сооружение в соответствии с действующими нормами проектирования, и от категории технического состояния этого здания или сооружения на момент назначения класса сейсмостойкости [23].

С течением времени способность здания или сооружения противостоять сейсмическим воздействиям понижается. Класс сейсмостойкости здания или сооружения по этой причине тоже может понижаться. Для предупреждения наступления негативных последствий от возможных сейсмических воздействий на здание или сооружение необходимо контролировать изменение его сейсмостойкости на протяжении всего жизненного цикла.

Класс сейсмостойкости здания или сооружения является интегрированной характеристикой, контроль изменения которой во времени необходим для принятия своевременных решений по предупреждению или минимизации последствий землетрясений и объективной оценки силы произошедшего землетрясения.

При прогнозе последствий землетрясений важно иметь карту возможных разрушений зданий и сооружений существующей застройки города при той или иной реализации прогнозируемого сейсмического воздействия, которая определяется сейсмической опасностью и уязвимостью зданий и сооружений. Сейсмическая опасность зависит от совокупности таких параметров, как величины ускорений грунта на различных частотах, длительности сейсмических сигналов, геологических условий территории города и некоторых других, а уязвимость зданий и сооружений определяется реальной сейсмостойкостью застройки города. Практическое определение прогнозируемой сейсмической опасности и прогнозируемой уязвимости сооружений имеет несколько приближений, в связи с чем и достоверность прогноза последствий разрушительных землетрясений может реально осуществляться лишь с той степенью достоверности, которая имеется для данного населённого пункта по отношению к прогнозу сейсмической опасности и уязвимости сооружений. В работе [24] изложены предложения по построению подобных карт возможных разрушений зданий и сооружений существующей застройки города при той или иной реализации прогнозируемого сейсмического воздействия.

Исследования в этом направлении стали основой для более широкого использования результатов в градостроительной деятельности после разработки и внедрения соответствующих методик выявления и оценки территорий повышенного риска в генеральном плане города [25; 26]. 
Пространственное устойчивое развитие Российской Федерации, её регионов требует изменения подходов к управлению и внедрения цифровых методов (цифровизации) в систему управления градостроительной деятельности, в связи с чем открываются новые возможности для восстановления на основе системы инженерно-сейсмометрических наблюдений и дальнейшего развития национальной системы мониторинга состояния и безопасности строительных объектов в период эксплуатации [27] как основы и составной части Информационной системы обеспечения градостроительной деятельности (ИСОГД).

\section{Лuтература}

1. Федеральный закон «Технический регламент о безопасности зданий и сооружений»от 30.12.2009 N 384-Ф3 [Электронный ресурс] // КонсультантПлюс. - Режим доступа: http://www.consultant.ru/document/cons_doc_ LAW_95720/17082021 (дата обращения17.08.2021).

2. ГОСТ 31937-2011 «Здания и сооружения. Правила обследования и мониторинга технического состояния» [Электронный ресурс] // Электронный фонд нормативно-технической и нормативно-правовой информации Консорциума «Кодекс». - Режим доступа: https://docs.cntd.ru/document/1200100941 (дата обращения13.08.2021)

3. Дорофеев, В.М. Мониторинг состояния зданий и сооружений существующей застройки городов, подверженных катастрофам природно-техногенного характера / В.М, Дорофеев // Проблемы безопасности при чрезвычайных ситуациях. Вып. 6. - М : ВИНИТИ, 1998. - С. 16-26.

4. Денисов, Б.Е. Определение динамических характеристик строительных конструкций по данным инженерно-сейсмометрических станций / Б.Е. Денисов, В.М. Дорофеев, 0.К. Погосян // Известия Академии наук Армянской ССР. - 1982. - XXXV. - № 6. - C. 47-50.

5. Дорофеев, B.M. 0 безопасной эксплуатации несущих конструкций зданий и сооружений / В.М. Дорофеев // Вестник Российского университета дружбы народов. Серия: Проблемы комплексной безопасности. - 2005. - № 2. - С. 44-52.

6. ГОСТ 34081-2017 «Здания и сооружения. Определение параметров основного тона собственных колебаний» [Электронный ресурс] // Электронный фонд нормативно-технической и нормативно-правовой информации Консорциума «Кодекс». - Режим доступа: https://docs.cntd.ru/document/1200157292 https://docs.cntd.ru/document/1200157292 (дата обращения 10.08.2021).

7. Пат. 2254426 C1 Российская Федерация, МПК E04G, G01M. Способ определения изменений напряженно-деформированного состояния конструкций здания или сооружения / Григорьев Ю.П., Гурьев В.В., Дмитриев А.Н., Дорофеев В.М., ГУП МНИИТЭП. - № 2004128916/03; заявл. 2004.10.04, опубл. 2005.06.20, Бюл. № 17. - 2 с.

8. Дорофеев, В.М. Мобильное устройство возбуждения динамической нагрузки для неразрушающих методов контроля строительных конструкций / В.М. Дорофеев, В.Г. Катренко // Промышленное и гражданское строительство. - 2009. - № 11. - С. 19-20.

9. Пат. 2292433 C1 Российская Федерация, МПК E04G23, G01M7. Способ определения изменений напряженно-деформированного состояния конструкций здания или сооружения сложной пространственной формы / Григорьев Ю.П., Гурьев В.В., Дмитриев А.Н., Дорофеев В.М. ; ГУП МНИИТЭП. - № 2005128100/03; заявл. 2005.09.09, опубл. 2007.01.27, Бюл. № $3 .-2$ c.

10. Пат. №2341623 С1 Российская Федерация, МПК Е04В1, $\mathrm{G01M/7.} \mathrm{Способ} \mathrm{определения} \mathrm{технического} \mathrm{состояния}$ строительных конструкций и/или их частей и элементов / Гурьев В.В., Дорофеев В.М., Лысов Д.А. ; ГУП МНИИТЭП. - № 2007144578/03; заявл. 2007.12.04, опубл. 2008.12.20, Бюл. № 35. -2 c.

11. Дорофеев, B.М. К вопросу о контроле технического состояния ферм крытого конькобежного центра в Крылатском / Дорофеев В.М., Лысов Д.А., Хайнер Е.П. // Промышленное и гражданское строительство. - 2009. - № 12. - С. 38-41.

12. ГОСТ 32019-2012 «Мониторинг технического состояния уникальных зданий и сооружений. Правила проектирования и установки стационарных систем (станций) мониторинга» [Электронный ресурс] // Электронный фонд нормативнотехнической и нормативно-правовой информации Консорциума «Кодекс». - Режим доступа: https://docs.cntd.ru/ document/1200100943 (дата обращения 21.08.2021).

13. Housner, G.W. Housner Earthquake Engineering-Some Early History / G.W. Housner // Proc. of the Golden Anniversary Workshop on Strong Motion Seismometry. - California. Los Angeles. Department of Civil Engineering, University of Southern California, 1983. - P. 7-16.

14. Инженерно-сейсмометрическая служба СССР / Под ред. Э.Е. Хачияна. - М : Наука, 1987. - 95 с.

15. Дорофеев, В.M. 0 разработке автоматизированной системы оперативного определения состояния зданий и сооружений города после сильного землетрясения / Дорофеев В.М., Пуховский А.Б. // Тезисы докладов международного симпозиума «Исследования и строительство в экстремальных условиях». Москва. 23-24 января. - М : МИИТ, 1996. - С. 17-18.

16. Дорофеев, В.М. Оптимизация сети инженерно-сейсмометрических станций / В.М. Дорофеев // Сейсмостойкое строительство. Серия 14. - 1980. - Вып. 7. - С. 26-29.

17. Дорофеев, В.М. Математическая задача оптимизации сети станций инженерно-сейсмометрической службы страны / В.М. Дорофеев // Исследования по теории сейсмостойкости сооружений. - М. : ЦНИИСК им. В.А. Кучеренко, 1983. - С. 91-104.

18. СП 330.1325800.2017 «Здания и сооружения в сейсмических районах. Правила проектирования инженерносейсмометрических станций» [Электронный ресурс] // Электронный фонд нормативно-технической и нормативно- 
правовой информации Консорциума «Кодекс». - Режим доступа: https://docs.cntd.ru/document/556793893 (дата обращения 16.08.2021).

19. Пат. № 2321836 С1 Российская Федерация, МПК G01M7. Станция контроля технического состояния здания или сооружения, его частей, конструкций, элементов конструкций и узлов соединения / Григорьев Ю.П., Гурьев В.В., Дмитриев А.Н., Дорофеев В.М. [и др.], ГУП МНИИТЭП. - № 2007110716/28, заявл. 2007.03.23, опубл. 2008.04.10, Бюл. № 10. - 2 с.

20. Пат. № 2654830 С1 Российская Федерация, МПК G01V1. Цифровая инженерно-сейсмометрическая станция с системой мониторинга технического состояния зданий или сооружений / Гурьев В.В., Дорофеев В.М., Лысов Д.А., Денисов А.С. [и др.] - № 2017122139, заявл. 2017.06.23, опубл. 2018.05.22, Бюл. № 15. - 2 с.

21. Пат. № 2654831 С1 Российская Федерация, МПК G01V1. Способ многоканальной регистрации сейсмических колебаний на инженерно-сейсмометрической станции / Гурьев В.В., Дорофеев В.М., Лысов Д.А., Денисов А.С. [и др.] - № 2017122140, заявл. 2017.06.23, опубл. 2018.05.22, Бюл. № 15. -2 c.

22. Пат. № 2655462 C1 Российская Федерация, МПК G01M7. Сейсмический прибор для измерения динамических воздействий при мониторинге технического состояния несущих конструкций зданий и сооружений / Гурьев В.В., Дорофеев В.М., Лысов Д.А., Денисов А.С. [и др.] - № 2017122141, заявл. 2017.06. 23, опубл. 2018.05. 28, Бюл. № 16. - 2 с.

23. СП 442.1325800.2019 Здания и сооружения в сейсмических районах. Оценка класса сейсмостойкости. Свод правил по проектированию и строительству. - М., 2019. - 13 с. // Электронный фонд нормативно-технической и нормативноправовой информации Консорциума «Кодекс». - Режим доступа: https://docs.cntd.ru/document/556793893 (дата обращения 15.08.2021).

24. Дорофеев, В.М. Прогноз последствий сильных землетрясений / В.М. Дорофеев, А.С. Денисов // Природные и техногенные риски. Безопасность сооружений. - 2019. - № 1. - С. 28-31.

25. Акбиев, Р.T. Перспективы комплексной оценки безопасности территорий городов и агломераций с позиций сейсмического риска / Р.Т. Акбиев // Природные и техногенные риски. Безопасность сооружений. - 2011. - № 1. - С. 55-64.

26. Методология комплексного инженерно-сейсмологического мониторинга состояния конструкций зданий и сооружений, включая площадки их размещения / Е.А. Рогожин, Н.К. Капустян, Г.А. Антоновская, Р.Т. Акбиев // Природные и техногенные риски. Безопасность сооружений. - 2011. - № 4. - C. 33-41.

27. Гурьев, В.В. 0 проблемах нормирования безопасности застроенных территорий в сейсмических районах / В.В Гурьев, В.М. Дорофеев // Фундаментальные, поисковые и прикладные исследования РАACH по научному обеспечению развития архитектуры, градостроительства и строительной отрасли
Российской Федерации в 2019 году : Сб. науч. тр. РААСН. - М. : ACB, 2020. - C. 157-178.

\section{References}

1. Federal'nyi zakon «Tekhnicheskii reglament o bezopasnosti zdanii i sooruzhenii»ot 30.12.2009 № 384-FZ [Federal law "Technical regulations on the safety of buildings and structures" from 30.12.2009 N 384-FZ]. Konsul'tantPlyus. Website. Access mode: http://www.consultant.ru/document/cons_doc_ LAW_95720/17082021 (Accessed 08/17/2021). (In Russ.)

2. GOST 31937-2011 «Zdaniya i sooruzheniya. Pravila obsledovaniya i monitoringa tekhnicheskogo sostoyaniya» ["Buildings and constructions. Rules of inspection and monitoring of the technical condition"]. Elektronnyi fond normativno-tekhnicheskoi i normativno-pravovoi informatsii Konsortsiuma «Kodeks» [Electronic fund of normative-technical and normative-legal information of the Consortium "Code"]. Access mode: https://docs.cntd.ru/document/1200100941 (Accessed 08/13/2021). (In Russ.)

3. Dorofeev V.M. Monitoring sostoyaniya zdanii i sooruzhenii sushchestvuyushchei zastroiki gorodov, podverzhennykh katastrofam prirodno-tekhnogennogo kharaktera [Monitoring of the state of buildings and structures of the existing development of cities prone to natural and man-made disasters]. In: Problemy bezopasnosti pri chrezvychainykh situatsiyakh. [Safety problems in emergency situations], Iss. 6. Moscow, VINITI Publ., 1998, pp. 16-26. (In Russ.)

4. Denisov B.E., Dorofeev V.M., Pogosyan 0.K. Opredelenie dinamicheskikh kharakteristik stroitel'nykh konstruktsii po dannym inzhenerno-seismometricheskikh stantsii [Determination of the dynamic characteristics of building structures according to the data of engineering seismometric stations]. In: Izvestiya Akademii nauk Armyanskoi SSR [Bulletin of the Academy of Sciences of the Armenian SSR], 1982, XXXV, no. 6, pp. 47-50. (In Russ.)

5. Dorofeev V.M. 0 bezopasnoi ekspluatatsii nesushchikh konstruktsii zdanii i sooruzhenii [0n safe operation of supporting structures of buildings and structures]. In: Vestnik Rossiiskogo universiteta druzhby narodov. Seriya: Problemy kompleksnoi bezopasnosti [Bulletin of the Peoples' Friendship University of Russia. Series: Problems of Integrated Security], 2005, no. 2, pp. 44-52. (In Russ.)

6. GOST 34081-2017 «Zdaniya i sooruzheniya. Opredelenie parametrov osnovnogo tona sobstvennykh kolebanii» [Buildings and constructions. Determination of parameters of the basic tone of natural oscillations]. Elektronnyi fond normativnotekhnicheskoi i normativno-pravovoi informatsii Konsortsiuma «Kodeks» [Electronic fund of normative-technical and normative-legal information of the Consortium "Code"]. Access mode: https://docs.cntd.ru/document/1200157292 (Accessed 08/10/2021). (In Russ.)

7. Grigor'ev Yu.P., Gur'ev V.V., Dmitriev A.N., Dorofeev V.M. Sposob opredeleniya izmenenii napryazhenno-deformirovannogo 
sostoyaniya konstruktsii zdaniya ili sooruzheniya [Method for determining changes in the stress-strain state of structures of a building or structure]. Patent RF no. $2254426 \mathrm{~S} 1$, decl. 04/10/20046, publ. 20/06/2005, Bull. no. 17, 2 p.

8. Dorofeev V.M., Katrenko V.G. Mobil'noe ustroistvo vozbuzhdeniya dinamicheskoi nagruzki dlya nerazrushayushchikh metodov kontrolya stroitel'nykh konstruktsii [Mobile device for excitation of a dynamicload for non-destructive methods of control of building structures]. In: Promyshlennoe $i$ grazhdanskoe stroitel'stvo [Industrial and Civil Engineering], 2009, no. 11. p. 19-20. (In Russ., abstr.in Engl.)

9. Grigoriev Yu.P., Guryev V.V., Dmitriev A.N., Dorofeev V.M. Patent RF no. 2292433 S1. Sposob opredeleniya izmenenii napryazhenno-deformirovannogo sostoyaniya konstruktsii zdaniya ili sooruzheniya slozhnoi prostranstvennoi formy [Method for determining changes in the stress-strain state of structures of a building or structure of complex spatial form]. Decl. 09/09/2005, publ. 01/27/2007, Bull. No. 3, 2 p.

10. Gur'ev V.V., Dorofeev V.M., Lysov D.A Patent RF no. 2341623 C1 Sposob opredeleniya tekhnicheskogo sostoyaniya stroitel'nykh konstruktsii i/ili ikh chastei i elementov [Method for determining the technical condition of building structures and / or their parts and elements]. Decl 12/04/2007, publ. 12/20/2008, Bull. № 35 .

11. Dorofeev V.M., Lysov D.A., Khainer E.P. Kvoprosu o kontrole tekhnicheskogo sostoyaniya ferm krytogo kon'kobezhnogo tsentra v Krylatskom [0n the issue of monitoring the technical condition of the indoor skating center trusses in Krylatskoye]. In: Promyshlennoe i grazhdanskoe stroitel'stvo [Industrial and Civil Engineering], 2009, no. 12, pp. 38-41. (In Russ., abstr.in Engl.)

12. GOST 32019-2012 «Monitoring tekhnicheskogo sostoyaniya unikal'nykh zdanii i sooruzhenii. Pravila proektirovaniya i ustanovki statsionarnykh sistem (stantsii) monitoringa» ["Monitoring of the technical condition of unique buildings and structures. Rules for the design and installation of stationary monitoring systems (stations)"]. Elektronnyi fond normativno-tekhnicheskoi i normativno-pravovoi informatsii Konsortsiuma «Kodeks» [Electronic fund of normative-technical and normative-legal information of the Consortium" Code"]. Access mode: https://docs.cntd.ru/document/1200100943 (Accessed 08/21/2021). (In Russ.)

13. Housner G.W. Housner Earthquake Engineering-Some Early History. Proc. of the Golden Anniversary Workshop on Strong Motion Seismometry. California, Los Angeles, Department of Civil Engineering, University of Southern California, 1983, pp. 7-16. (In Engl.)

14. In E.E. Khachiyan (ed.) Inzhenerno-seismometricheskaya sluzhba [Engineering and seismometric service of the USSR]. Moscow, Nauka Publ., 1987, 95 p. (In Russ.)

15. Dorofeev V.M. A.B. Pukhovskii 0 razrabotke avtomatizirovannoi sistemy operativnogo opredeleniya sostoyaniya zdanii i sooruzhenii goroda posle sil'nogo zemletryaseniya [0n the development of an automated system for the operational determination of the state of buildings and structures of the city after a strong earthquake]. In: Tezisy dokladov mezhdunarodnogo simpoziuma «Issledovaniya $i$ stroitel'stvo $v$ ekstremal'nykh usloviyakh» [Abstracts of the international symposium "Research and construction in extreme conditions"]. Moscow. January 23-24. Moscow, MIIT Publ., 1996, pp. S. 17-18. (In Russ.)

16. Dorofeev V.M. Optimizatsiya seti inzhenernoseismometricheskikh stantsii [0ptimization of the network of engineering seismometric stations]. In: Seismostoikoe stroitel'stvo. Seriya 14 [Earthquake-resistant construction. Series 14], 1980, Iss. 7, pp. 26-29. (In Russ.)

17. Dorofeev V.M. Matematicheskaya zadacha optimizatsii seti stantsii inzhenerno-seismometricheskoi sluzhby strany [Mathematical problem of optimization of the network of stations of the engineering and seismometric service of the country]. In: Issledovaniya po teorii seismostoikosti sooruzhenii [Mathematical problem of optimization of the network of stations of the engineering and seismometric service of the country]. Moscow, TsNIISK im. V.A. Kucherenko Publ., 1983, pp. 91-104. (In Russ.)

18. SP 330.1325800 .2017 «Zdaniya i sooruzheniya v seismicheskikh raionakh. Pravila proektirovaniya inzhenernoseismometricheskikh stantsii» ["Buildings and constructions in seismic countries. Rules of design of engineering and seismometric stations"]. Elektronnyi fond normativnotekhnicheskoi i normativno-pravovoi informatsii Konsortsiuma «Kodeks» [Electronic fund of normative-technical and normative-legal information of the Consortium" Code "]. Access mode: https://docs.cntd.ru/document/556793893 (Accessed 16.08.2021). (In Russ.)

19. Grigor'ev Yu.P., Gur'ev V.V., Dmitriev A.N., Dorofeev V.M. [et al.]. Patent RF no. 2321836 S1 Stantsiya kontrolya tekhnicheskogo sostoyaniya zdaniya ili sooruzheniya, ego chastei, konstruktsii, elementov konstruktsii i uzlov soedineniya [Station for monitoring the technical condition of a building or structure, its parts, structures, structural elements and connection units]. Decl. 03/23/2007, publ. 04/10/2008, Bull. no. $10,2 \mathrm{p}$.

20. Gur'ev V.V., Dorofeev V.M., Lysov D.A., Denisov A.S. [et al.] Tsifrovaya inzhenerno-seismometricheskaya stantsiya $s$ sistemoi monitoringa tekhnicheskogo sostoyaniya zdanii ili sooruzhenii [Digital engineering seismometric station with a system for monitoring the technical condition of buildings or structures]. Patent RF no. 2654830 S1, decl. 06/23/2017, publ. 05/22/2018, Bull. no. 15, 2 p.

21. Gur'ev V.V., Dorofeev V.M., Lysov D.A., Denisov A.S. [et al.] Sposob mnogokanal'noi registratsii seismicheskikh kolebanii na inzhenerno-seismometricheskoi stantsii [Method of multichannel registration of seismic vibrations at an engineering seismometric station]. Patent RF no. 2654831 S1, decl. 06/26/2017, publ. 05/22/2018, Bull. no. 15, 2 p. 
22. Gur'ev V.V., Dorofeev V.M., Lysov D.A., Denisov A.S. [et al.]. Seismicheskii pribor dlya izmereniya dinamicheskikh vozdeistvii pri monitoringe tekhnicheskogo sostoyaniya nesushchikh konstruktsii zdanii i sooruzhenii [Seismic device for measuring dynamic effects when monitoring the technical state of load-bearing structures of buildings and structures] Pat. RF no. 2655462 S1, decl. 06/23/2017, publ. 05/28/2018, Bull. no. 16, 2 p.

23. SP 442.1325800.2019 Zdaniya i sooruzheniya $v$ seismicheskikh raionakh. Otsenka klassa seismostoikosti. Svod pravil po proektirovaniyu i stroitel'stvu [Buildings and structures in seismic areas. Assessment of the seismic resistance class. A set of rules for design and construction]. Moscow, 2019, 13 p. Elektronnyi fond normativno-tekhnicheskoi i normativnopravovoi informatsii Konsortsiuma «Kodeks» [Electronic fund of normative-technical and normative-legal information of the Consortium" Code"]. Access mode: https://docs.cntd.ru/ document/556793893 (Accessed 15.08.2021). (In Russ.)

24. Dorofeev V.M., Denisov A.S. Prognoz posledstvii sil'nykh zemletryasenii [Forecast of the consequences of strong earthquakes]. In: Prirodnye i tekhnogennye riski. Bezopasnost' sooruzhenii [Natural and technogenic risks. Safety of structures], 2019, no. 1, pp. 28-31. (In Russ., abstr.in Engl.)

25. Akbiev R.T. Perspektivy kompleksnoi otsenki bezopasnosti territorii gorodov i aglomeratsii s pozitsii seismicheskogo riska [Prospects for a comprehensive assessment of the safety of the territories of cities and agglomerations from the standpoint of seismic risk]. In: Prirodnye i tekhnogennye riski. Bezopasnost' sooruzhenii [Natural and technogenic risks. Safety of structures], 2011, no. 1, pp. S. 55-64. . (In Russ., abstr.in Engl.)

26. Rogozhin E.A., Kapustyan N.K., Antonovskaya G.A., Akbiev R.T. Metodologiya kompleksnogo inzhenernoseismologicheskogo monitoringa sostoyaniya konstruktsii zdanii i sooruzhenii, vklyuchaya ploshchadki ikh razmeshcheniya [Methodology of integrated engineering and seismological monitoring of the state of structures of buildings and structures, including the sites for theirlocation]. In: Prirodnye i tekhnogennye riski. Bezopasnost' sooruzhenii [Natural and technogenic risks. Safety of structures], 2011, no. 4, pp. 33-41. (In Russ., abstr.in Engl.)

27. Gur'ev, V.V. 0 problemakh normirovaniya bezopasnosti zastroennykh territorii $v$ seismicheskikh raionakh [0n the problems of standardizing the safety of built-up areas in seismic regions]. In: Fundamental'nye, poiskovye i prikladnye issledovaniya RAASN po nauchnomu obespecheniyu razvitiya arkhitektury, gradostroitel'stva i stroitel'noi otrasli Rossiiskoi Federatsii v 2019 godu : Sb. nauch. tr. RAASN [Collection of scientific papers of RAACS "Fundamental, exploratory and applied research of the RAASN on scientific support for the development of architecture, urban planning and the construction industry of the Russian Federation in 2019"]. Moscow, ASV Publ., 2020, pp. 157-178. (In Russ., abstr.in Engl.)

Гурьев Владимир Владимирович (Москва). Доктор технических наук, профессор. Руководитель института строительной механики сейсмостойкого строительства и защиты от стихийных бедствий ФГБУ «Центральный научно-исследовательский и проектный институт Министерства строительства и жилищно-коммунального хозяйства Российской Федерации» (119331, Москва, просп. Вернадского, д. 29. ЦнИИПМинстроя России). Эл.почта: 89150902767@mail.ru.

Дорофеев Владимир Михайлович (Москва). Кандидат физико-математических наук, старший научный сотрудник. Главный специалист ФАУ «Федеральный центр нормирования, стандартизации и технической оценки соответствия в строительстве» (101000, Москва, Фуркасовский пер., д.6. ФАУ «ФЦС»). Эл. почта: vm.dorofeev2015@yandex.ru.

Лысов Дмитрий Анатольевич (Москва) Кандидат технических наук. Заместитель руководителя центра по безопасной эксплуатации зданий и сооружений АО «Центральный научно-исследовательский и проектно-экспериментальный институт промышленных зданий и сооружений» (127238, Москва, Дмитровское шоссе, д. 46, корп.2. ЦНИИПромзданий). Эл. почта: Ld.mnipitep@rambler.ru.

Акбиев Рустам Тоганович (Москва). Кандидат технических наук. Руководитель Департамента комплексной градостроительной безопасности ФГБУ «Центральный научно-исследовательский и проектный институт Министерства строительства и жилищнокоммунального хозяйства Российской Федерации», (101000, Москва, проспект Вернадского, д. 29. ЦНИИП Минстроя России). Эл. почта: akbi.rust@gmail.com. 
Guriev Vladimir V. (Moscow). Doctor of Technical Sciences, Professor, Advisor of RAACS. Head of the Institute of Structural Mechanics of Earthquake-resistant Construction and Protection from Natural Disasters FGBU "Central Research and Design Institute of the Ministry of Construction and Housing and Communal Services of the Russian Federation" (29 Vernadsky Avenue, Moscow, 119331. FSBI " TSNIIP of the Ministry of Construction of Russia") E-mail: 89150902767@mail.ru.

Dorofeev Vladimir M. (Moscow). Candidat of Physical and Mathematical Sciences, Senior scientific researcher. Chief Specialist of FAU "Federal centre for regulation, standardization and technical assessment in construction" (Furkasovskylane, build. 6, Moscow, 101000. FAU "FCC").E-mail: vm.dorofeev2015@yandex.ru.

Lysov Dmitriy A. (Moscow). Candidate of Technical Sciences, Ph.D. Deputy head of the Center for the Safe Operation of Buildings and Structures, JSC TsNIIPromzdaniy. A0 "Central Research and Development Design and Experimental Institute of Industrial Buildings and Structures". (Russian Federation, 127238, Moscow, Dmitrovskoe shosse, building 46, building 2), e-mail: Ld.mnipitep@ rambler.ru.

Akbiev Rustam T. (Moscow). Candidate of Technical Sciences, Head of the Department of Integrated Urban Planning Security FGBU "Central Research and Design Institute of the Ministry of Construction and Housing and Communal Services of the Russian Federation", (29 Vernadsky Avenue, Moscow, 119331. FSBI " TSNIIP of the Ministry of Construction of Russia") Tel +7 926075 1111, Email:akbi.rust@gmail.com. 